\title{
Restorative proctocolectomy with an ileoanal pouch: the role of laparoscopy
}

\author{
L. Delgado Plasencia, I. Arteaga González, E. M. López-Tomassetti Fernández, A. Martín Malagón, \\ H. Díaz Luis and A. Carrillo Pallarés
}

Department of Surgery. University Hospital of Canarias (HUC). Santa Cruz de Tenerife, Spain

\begin{abstract}
Objectives: the aim of this retrospective study was to evaluate early experience with laparoscopic restorative proctocolectomy by analyzing the perioperative results of surgical treatment.

Patients and methods: seven major surgeries were performed in six patients with familial adenomatous polyposis and ulcerative colitis. All procedures were performed under laparoscopy at our third-level hospital from June 2003 to October 2004.

Results: mean surgical time was $287.5 \pm 80.7 \mathrm{~min}$, and median blood loss was $300 \pm 249.0 \mathrm{cc}$. There were no conversions; return of peristalsis began at $32 \pm 12.4 \mathrm{~h}$; average time to first oral intake was $64.0 \pm 32.8 \mathrm{~h}$, and mean duration of hospital stay was $9.3 \pm 1.2$ days. There was one case of perineal sepsis due to ileal pouch-anal anastomotic leakage, which was successfully treated with oral intake restriction, parenteral nutrition, and intrarectal drainage. The most common postoperative complication was postoperative ileus.

Conclusions: we believe that the laparoscopic approach to restorative proctocolectomy may be considerably improved in our center. Particular aspects for improvement include efforts to achieve lower operating and hospitalization times to equate our results with those reported by multicenter studies for laparoscopic colon cancer surgery. In our opinion, learning and further training opportunities should be encouraged to improve surgeon experience in the field of laparoscopy, preferably at centers specializing in restorative proctocolectomy.
\end{abstract}

Key words: Restorative proctocolectomy. Ileoanal pouch. Laparoscopy. Surgery.

Delgado Plasencia L, Arteaga González I, López-Tomassetti Fernández E, Martín Malagón A, Díaz Luis H, Carrillo Pallarés A. Restorative proctocolectomy with an ileoanal pouch: the role of laparoscopy. Rev Esp Enferm Dig 2006; 98: 420-428.

Recibido: 26-08-05.

Aceptado: 12-01-06.

Correspondencia: Luciano Delgado Plasencia. Departamento de Cirugía. Hospital Universitario de Canarias. C/ Ofra, s/n. 38320 La Cuesta, La Laguna. Santa Cruz de Tenerife. Fax: 922 653808. e-mail: luciano_delgado1@yahoo.es / drtomassetti@wanadoo.es.

\section{INTRODUCTION}

Restorative proctocolectomy (RP) with an ileoanal pouch was first described in 1978 by Parks and Nicholls. After two decades of extensive worldwide disclosure, this technique has offered excellent results, which may improve even further. Even though many years have passed, it still is the technique of choice for patients with familial adenomatous polyposis (FAP) or ulcerative colitis requiring surgery.

Laparoscopic techniques have revolutionized surgery. As a result of improvements in laparoscopic techniques and the development of new instruments, laparoscopic surgery has emulated virtually every open surgical procedure. Despite the clear advantages of laparoscopy for colorectal cancer surgery, great controversy surrounds its actual advantages in the area of RP since, other than its evident improvement of esthetics; most studies have been unable to clearly prove that laparoscopy is preferable to open surgery, due both to the complexity of the procedure and the prolonged learning curve required (1).

The aim of our research was to analyze the initial results obtained with the implementation of laparoscopic techniques for the surgical treatment of FAP and ulcerative colitis, with a special focus on the complications and technical problems its implementation results in.

\section{PATIENTS AND METHODS}

Between June 2003 and October 2004 seven major surgeries were performed on six patients in our third-level hospital. Five underwent one-stage surgery, and a sixth underwent an initial total colectomy, with proctectomy and tract reconstruction performed in a second stage.

Each operation was performed by three surgeons highly experienced in laparoscopic surgery for colorectal cancer. All three had completed at least 20 of these surgical 
procedures -the initial learning curve required for this technique both in our opinion and that of other authors.

Patients included in the study were surgery candidates with FAP or ulcerative colitis. As of the start date of the study, no patients were excluded.

Variables studied were divided into: demographic -age, sex, body mass index (BMI), American Society of Anesthesiologists (ASA) score, and previous laparotomies-; intraoperative (operative time, blood loss, conversion, complications), and postoperative (peristalsis, return of oral intake, hospital stay, major and minor complications, re-operations, and readmissions).

Major complications were defined as those potentially life-threatening or those leading to re-operation. All others were considered minor complications.

Data on the variables collected were stored in a database for later statistical analysis using the SPSS 11.0. software package.

\section{Surgical technique}

Under general anesthesia, patients were placed in a lithotomy position, with arms alongside the body and the hip minimally flexed (modified Lloyd Davis position). Each patient received a dose of antibiotic prophylaxis $\left(\right.$ Mefoxitin ${ }^{\circledR}$ ). The surgeon and the camera assistant were positioned on the opposite side to dissection. Two monitors were placed, one on either side of the patient. Pneumoperitoneum was performed with a Veres needle at 14 $\mathrm{mmHg}$. Six trocars were placed as illustrated in the following diagram (Fig. 1).

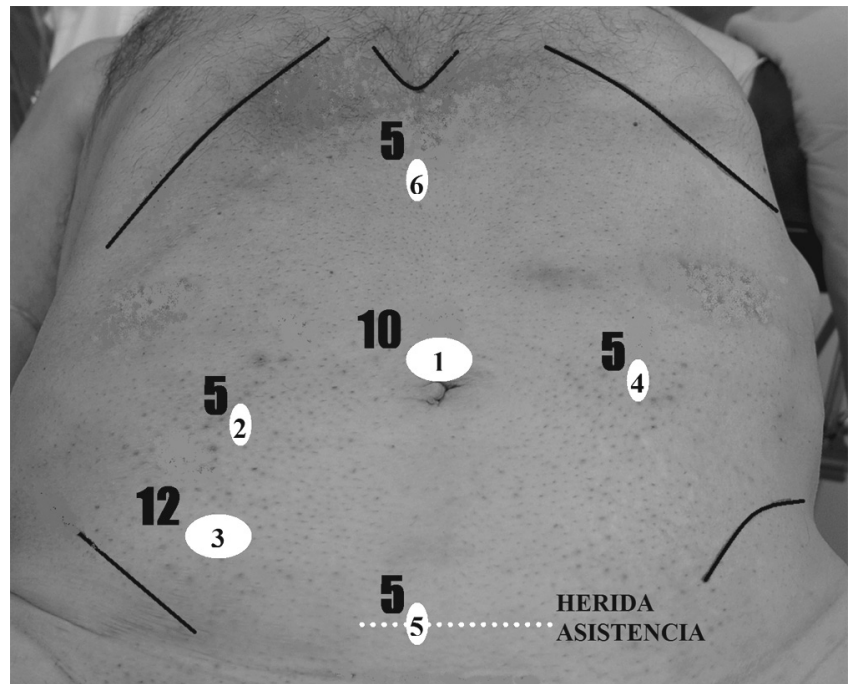

Fig. 1. Trocar placement and auxiliary incision for laparoscopic RP. Circled numbers indicate trocar placement order.

Disposición de los trocares y herida asistencia para la PCR laparoscópica. El orden de introducción de los trocares se señala en el interior de la esfera.
With the patient in Trendelenburg's position and rotated to the right, dissection commenced with a combined ligation of the inferior mesenteric vessels using an Endogia Universal ${ }^{\circledR}$ stapler with EGIA II $45-2.5^{\circledR}$ load. The entire left colon was mobilized mediolaterally by blunt dissection through the posterior avascular plane. Next, acute rectal sectioning was performed between the pelvic and rectal fascia up to the anorectal junction, sectioning the rectum some two centimeters above the pectineal line with an EGIA II 60-3.5 ${ }^{\oplus}$-loaded Endogia Universal ${ }^{\circledR}$ stapler. After section of the rectum, the left colon was released from Toldt's fascia. When dissection approached the splenic flexure, the surgeon placed himself between the legs of the patient to work at ports 4 and 6 (left half of the abdomen and subxiphoid), with the monitor above the patient's left shoulder. Dissection continued counter-clockwise, proceeding to the ligation of the vascular pedicle of middle colic vessels and the mobilization of the transverse colon, firstly via the avascular plane and then at the gastrocolic ligament.

Next, the surgeon and camera assistant positioned themselves on the left side for the right-colon dissection, performing first a hemostasis of the ileocolic vessels and then proceeding towards the hepatic flexure.

Once mobilized, the colon was extracted by means of a Pfannenstiel incision, approximately $4 \mathrm{~cm}$ in length, protected with a plastic bag through which a J-pouch of approximately $18 \mathrm{~cm}$ was made (Fig. 2).

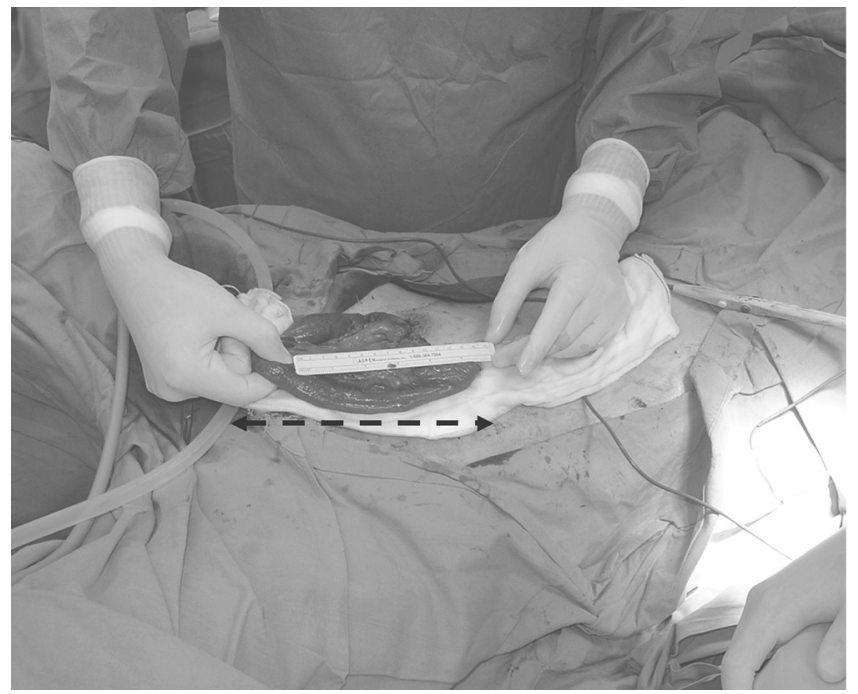

Fig. 2. Extracorporeal pouch construction (length approx. $20 \mathrm{~cm}$ ) through the auxiliary incision.

En la imagen se aprecia la construcción extracorpórea del reservorio (aproximadamente $20 \mathrm{~cm}$ de longitud) por la herida de asistencia.

Finally, an intracorporeal pouch-anal anastomosis was performed with a Premium CEEA $28^{\circledR}$ circular stapler. In all cases anastomosis was performed $1-2 \mathrm{~cm}$ above the dentate line in order to preserve both anorectal sensitivity and the rectoanal inhibitory reflex. All patients had a RIF protective ileostomy. 


\section{RESULTS}

Mean duration of surgery: $287.5 \pm 80.7 \mathrm{~min}$; blood loss: $300 \pm 249.0 \mathrm{cc}$; conversions: none; return of peristalsis: 32 $\pm 12.4 \mathrm{~h}$; mean time to oral intake: $64.0 \pm 32.8 \mathrm{~h}$; mean hospital stay: $9.3 \pm 1.2$ days. The most frequent postoperative complication was postoperative ileus, which occurred in all cases and was treated conservatively by placing a Foley catheter through the ileostomy (Table I). There was one case of ileoanal pouch dehiscence with perineal sepsis, which was treated conservatively by restricting oral intake, parenteral nutrition, and intra-rectal drainage to minimize the chances for fistulous tract development.

\section{DISCUSSION}

The feasibility of laparoscopic RP was first observed by Peters (2) in two patients with ulcerative colitis. Others have later described laparoscopic RP as being a safe and effective technique for managing patients with FAP and inflammatory intestinal disease $(1,3-7)$. This is not its only application, and satisfactory results have also been seen with surgery for constipation, management of rectal prolapse (8-11), and malignancies, although long-term results are yet to be ensured in the latter case (12).

The aim of laparoscopic treatment for RP is to improve the results of open surgery. Advantages include: improved esthetics, reduced pain, earlier mobilization, fewer surgical wound infections, rapid return of peristalsis, and earlier discharge and return to normal daily routines. Furthermore, its potential for avoiding adhesions and thus intestinal obstructions, infertility, and chronic abdominal pains, of particular importance for younger patients, must not be overlooked $(13,14)$.

Laparoscopic RP is a reproducible technique, while a long learning curve is required due to its complexity and duration. Some authors estimate the complete learning curve to require between 11 and 15 laparoscopic colectomies (15), while Fleshman et al. (16) suggest that for such a complicated procedure it may well take more than 50 surgeries before both complication rates and surgery duration are reduced.

Although twenty procedures have often been considered sufficient, providing the surgeon is instructed or supervised by a surgeon with expertise in the field, a recent study has found that results (operative time, conversion rate) are related to the learning curve, and considers the full learning curve for right colon procedures to require 55 cases, and then 65 cases for left colon procedures (17).

The main problem we encountered for technique implementation was the duration of surgery, which we found to be longer than in other reports published. Although duration will obviously decrease as experience increases, we believe that making time for benign procedures lasting up to six hours will be difficult in our health services, where colorectal cancer procedures are currently in high demand.

Technically speaking, laparoscopy provided excellent visualization of the rectum and the colic flexures. Similarly to surgery for tumor diseases, rectal dissection was performed through the mesorectal plane. We believe that this makes dissection easier, and allows a reduction in blood loss and a full preservation of the autonomic plexus. A further advantage of laparoscopy is that it enables a correct pouch-anal anastomosis construction. The most difficult part, however, proved to be mobilization of the transverse colon, due to the short distance between the optics and working area, and difficulties to locate the correct dissection plane between the mesocolon and pancreas. Both graspers for "gripping" without "tearing", such as Endo Clinch, and a visual angle of $25^{\circ}$ clearly aid surgery.

Early postoperative recovery and return to normal daily routines are considered the most important benefits of laparoscopic surgery. However, in addition of psychological benefits, improved esthetic results are the most appreciated benefits of surgical laparoscopy particularly by younger, active, and highly motivated patients (7). As has recently been reported, awareness regarding the specific demand for information of typically young patients with inflammatory diseases is also important (18).

Table I. Patient variables, results and complications

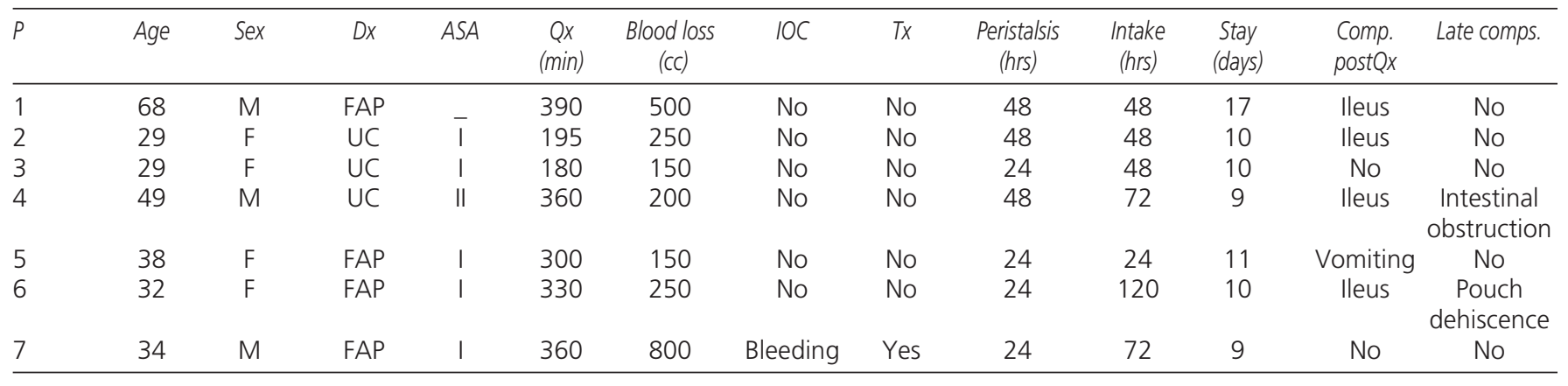

Dx: diagnosis; Qx: surgical time; IOC: intraoperative complications; Tx: transfusions; Comp postQx: postoperative complications; M: male; F: female; FAP: familial adenomatous polyposis; UC: ulcerative colitis. 
Table II. Results reported in other series

\begin{tabular}{|c|c|c|c|c|c|c|c|c|c|c|c|c|}
\hline Paper & $n$ & Age & $\begin{array}{l}\text { Surgery } \\
\text { (min) }\end{array}$ & $\begin{array}{l}\text { Blood loss } \\
\text { (cc) }\end{array}$ & $T x$ & $\begin{array}{l}\text { Minor } \\
\text { comps. }\end{array}$ & $\begin{array}{l}\text { Major } \\
\text { comps. }\end{array}$ & Ileostomy & $\begin{array}{c}\text { Tolerance } \\
\text { (hrs) }\end{array}$ & $\begin{array}{l}\text { Stay } \\
\text { (days) }\end{array}$ & Indication & Conv. \\
\hline Kienle & $\begin{array}{c}59 \\
(39 M ; 20 F)\end{array}$ & - & 320 & 500 & $\begin{array}{c}\text { Yes } \\
(27.1 \%)\end{array}$ & $9(15.3 \%)$ & $11(18.6 \%)$ & $\begin{array}{c}27 \\
(45.7 \%)\end{array}$ & - & 15 & $\begin{array}{l}37 \text { UC } \\
22 \text { FAP }\end{array}$ & 5 \\
\hline Maartense & 29 & 29 & 245 & No & No & $\begin{array}{l}\text { Three } \\
\text { infections }\end{array}$ & 3 & - & - & 10 & - & 0 \\
\hline Seshadri & $\begin{array}{c}15 \\
\text { (5M: 10F) }\end{array}$ & 47 & 400 & No & No & 1 & 5 & - & - & 8 & $\begin{array}{c}9 \text { UC } \\
6 \text { Crohn }\end{array}$ & 0 \\
\hline Thubault & $3(3 F)$ & 27.3 & 451.6 & 391.6 & No & $\begin{array}{l}1 \text { AUR and } \\
\text { nausea }\end{array}$ & 0 & - & 4 & 10 & 3 Crohn & 0 \\
\hline
\end{tabular}

Tx: transfusions; Conv: conversions; M: male; F: female; FAP: familial adenomatous polyposis; UC: ulcerative colitis; AUR: acute urine retention.

Other benefits have been ascribed to the results of laparoscopy compared to laparotomy, such as reductions in surgical complications, in steroid-dependent patients, and in adhesion formation, a lower incidence of incision hernias, and immune preservation $(7,13)$.

Although initial reports showed MIS to be beneficial concerning hospital stay and the outcomes of postoperative ileus, they also reported higher conversion and transfusion rates when compared to conventional surgery (19). Other studies have since reported that laparoscopy favors an earlier return of peristalsis and shorter hospital stays (20-27) (Table II).

In our experience, laparoscopic techniques did not significantly reduce hospital stay. This was greatly due to postoperative ileus problems, which were encountered in every case. Possible reasons for this are an inadequate construction of protective ileostomy in the lower right trocar area, and the effects of pneumoperitoneum in surgeries which lasted for almost 5 hours.

It has been found that both high corticoid dosages and obesity are additional and independent risk factors for septic complications in RP. Despite controversy in the literature regarding the need for protective ileostomies, it would seem reasonable to consider their convenience in patients undergoing high-dosage immunosuppressive treatments and in those with a high BMI, particularly in difficult intraoperative situations and when anastomosis is performed under tension $(10,28)$.

Unquestionably, the risk of complications and postoperative morbidity is inversely proportional to experience, technique, and instrument improvements. Nicholls considered that overall complications in RP ranged between 2 and $50 \%$ (29). However, none of the cases in our series required re-operation, and the proportion of major complications was low. Three patients were readmitted, two for vomiting related to ileostomy malfunction, and the third with a pelvic abscess due to anastomotic dehiscence, which was solved by transrectal drainage.

To conclude, and in the light of our results, we believe that laparoscopic RP must first prove to reduce operative time and hospital stay before it can be implemented even by groups specialized in laparoscopic colorectal surgery as the technique of choice for the treatment of FAP and ulcerative colitis. Furthermore, long-term results must also prove comparable to those of conventional surgery.

We share the view that, until these patients have been followed up in the long term, we will not be able to evaluate many of the characteristic benefits of laparoscopy. Other complications such as adhesive obstructions and the forming of eventrations are slow to appear and are characteristic of open surgery (30) and can therefore be avoided with laparoscopic surgery, especially in young patients with long life expectancies.

\section{REFERENCES}

1. Marcello PW, Milsom JW, Wong SK, Hammerhofer KA, Goormastic M, Church JM, et al. Laparoscopic restorative proctocolectomy: a case-matched comparative study with open restorative proctocolectomy. Dis Colon Rectum 2000; 43: 604-8.

2. Peters WR. Laparoscopic total proctocolectomy with creation of ileostomy for ulcerative colitis: report of two cases. J Laparoendosc Surg 1992; $2: 175$.

3. Wexner SD, Johansen OB, Nogueras JJ, Jagelman DG. Laparoscopic total abdominal colectomy: a prospective trial. Dis Colon Rectum 1992; 35: 651-5.

4. Schmitt SL, Cohen SM, Wexner SD, Nogueras JJ, Jagelman DG. Does laparoscopic-assisted ileal pouch anal anastomosis reduce the length of hospitalization? Int J Colorect Dis 1994; 9: 134-7.

5. Araki Y, Ishibashi N, Ogata Y, Shirouzu K, Isomoto H. The usefulness of restorative laparoscopic-assisted total colectomy for ulcerative colitis. Kurume Med J 2001; 48: 99-103.

6. Hashimoto A, Funayama Y, Naito H, Fukushima K, Shibata C, Naitoh $\mathrm{T}$, et al. Laparoscopic-assisted versus conventional restorative proctocolectomy with rectal mucosectomy. Surg Today 2001; 31: 210-4.

7. Dunker MS, Bemelman WA, Slors JFM, van Duijvendijk P, Grouma DJ. Functional outcome, quality of life, body image, and cosmesis in patients after assisted-assisted and conventional restorative proctocolectomy: a comparative study. Dis Colon Rectum 2001; 44: 1800-7.

8. Yoshioka K, Ogunbiyi OA, Keighley MR. Pouch perineal rectosig- 
moidectomy gives better functional results than conventional rectosigmoidectomy in elderly patients with rectal prolapse. Br J Surg 1998; 85: 1525-6.

9. Van Duijvendijk P, Slors JF, Taat CW, Bemelman WA, van Lochem LT. Proctocolectomy with an ileal pouch-anal anastomosis; results from 100 consecutive patients in the Academic Medical Center at Amsterdam, 1994-1999. Ned Tijdschr Geneeskd 2000; 144: 612-6.

10. Fazio VW, Ziv Y, Church JM, Oakley JR, Lavery IC, Milsom JW, et al. Ileal pouch-anal anastomoses complications and function in 1005 patients. Ann Surg 1995; 222:120-7.

11. Radice E, Nelson H, Devine RM, Dozois RR, Nivatvongs S, Pemberton JH, Wolff BG, et al. Ileal pouch-anal anastomosis in patients with colorectal cancer: long-term functional and oncologic outcomes. Dis Colon Rectum 1998; 41: 11-7.

12. Romanos J, Samarasekera DN, Stebbing JF, Jewell DP, Kettlewell MG, Mortensen NJ. Outcome of 200 restorative proctocolectomy operations: the John Radcliffe Hospital experience. Br J Surg 1997; 84: 814-8.

13. Sardinha TC, Wexner SD. Laparoscopy for inflammatory bowel disease: pros and cons. World J Surg 1998; 22: 370-4

14. Duepree HJ, Senagore AJ, Delaney CP. Does means of access affect the incidence of small bowel obstruction and ventral hernia after bowel resection? Laparoscopy versus laparotomy. J Am Coll Surg 2003; 197: $177-81$.

15. Veldkamp R, Gholghesaei M, Bonjer HJ, Meijer DW, Buunen M, Jeekel J, et al.; European Association of Endoscopic Surgery (EAES). Laparoscopic resection of colon Cancer: consensus of the European Association of Endoscopic Surgery (EAES).

16. Fleshman JW, Nelson H, Peters WR, Kim HC, Larach S, Boorse RR, et al. Early results of laparoscopic surgery for colorectal cancer. Retrospective analysis of 372 patients treated by Clinical Outcomes of Surgical Therapy (COST) Study Group. Dis Colon Rectum 1996; 39: S53-8.

17. Tekkis PP, Senagore AJ, Delaney CP, Fazio VW. Evaluation of the learning curve in laparoscopic colorectal surgery: comparison of right-sided and left-sided resections. Ann Surg 2005; 242: 83-91.

18. Casellas F, Fontanet G, Borruel N, Malagelada JR. The opinion of patients with inflammatory bowel disease on healthcare received. Rev Esp Enferm Dig 2004; 96: 174-84.
19. Wexner SD, Cera SM. Laparoscopic surgery for ulcerative colitis Surg Clin North Am 2005; 85: 35-47.

20. Kienle P, Weitz J, Benner A, Herfarth C, Schmidt J. Laparoscopically assisted colectomy and ileoanal pouch procedure with and without protective ileostomy. Surg Endosc 2003; 17: 716-20.

21. Kienle P, Z'graggen K, Schmidt J, Benner A, Weitz J, Buchler MW. Laparoscopic restorative proctocolectomy. Br J Surg 2005; 92: 8893.

22. Gill T, Karantana A, Rees J, Pandey S, Dixon AR. Laparoscopic proctocolectomy with restorative ileal-anal pouch. Colorectal Dis 2004; 6: $458-61$.

23. Maartense S, Dunker MS, Slors JF, Cuesta MA, Gouma DJ, van Deventer SJ, et al. Hand-assisted laparoscopic versus open restorative proctocolectomy with ileal pouch anal anastomosis: a randomized trial. Ann Surg 2004; 240: 984-91.

24. Maartense S, Bemelman WA, Gerritsen van der Hoop A, Meijer DW, Gouma DJ. Hand-assisted laparoscopic surgery (HALS): a report of 150 procedures. Surg Endosc 2004; 18: 397-401.

25. Nakajima K, Lee SW, Cocilovo C, Foglia C, Sonoda T, Milsom JW Laparoscopic total colectomy: hand-assisted vs standard technique. Surg Endosc 2004; 18: 582-6.

26. Seshadri PA, Poulin EC, Schlachta CM, Cadeddu MO, Mamazza J. Does a laparoscopic approach to total abdominal colectomy and proctocolectomy offer advantages? Surg Endosc 2001; 15: 837-42. Epub 2001 May 7.

27. Thibault C, Poulin EC. Total laparoscopic proctocolectomy and laparoscopy-assisted proctocolectomy for inflammatory bowel disease: operative technique and preliminary report. Surg Laparosc Endosc 1995; 5: 472-6.

28. Efron JE, Uriburu P, Wexner SD, Pikarsky A, Hamel C, Weiss EG, et al. Restorative proctocolectomy with ileal pouch anal anastomosis in obese patients. Obes Surg 2001; 11: 246-51.

29. Nicholls RJ, Gatzen C. Complications of pouch surgery. In: Beynon J, Carr ND, editors. Recent advances in coloproctology. Berlin: Springer Verlag, 1999. p. 1-29.

30. Perea García J, Turégano Fuentes F, Quijada García B, Trujillo A, Cereceda $\mathrm{P}$, Díaz Zorita B, et al. Adhesive small bowel obstruction: predictive value of oral contrast administration on the need for surgery. Rev Esp Enferm Dig 2004; 96: 191-200. 